\title{
Miguel Nazar Haro y la guerra sucia en México
}

Carlos Fernando López de la Torre'
Universidad Nacional Autónoma de México

Artículo de reflexión derivado de investigación

Recibido: abril 19 de 2013- Aprobado: mayo 24 de 2013

\section{Resumen}

Miguel Nazar Haro es recordado como uno de los principales ejecutores de la guerra sucia en México entre las décadas de 1960 y 1980. Partícipe directo en la tortura y desaparición de opositores políticos al régimen, fue además fundador de la Brigada Blanca, organización paramilitar encargada de aniquilar a la guerrilla urbana. El artículo indaga cómo Nazar Haro participó en la lucha del Estado mexicano contra la violencia revolucionaria, atendiendo el ambiente ideológico que justificó la violencia estatal y sus mecanismos de represión.

Palabras clave: México, Miguel Nazar Haro, guerra sucia, contrainsurgencia, tortura

\section{Miguel Nazar Haro and the dirty war in Mexico}

\begin{abstract}
:
Miguel Nazar is remembered as one of the main actors in the dirty war in the 60's and 70's decades. He participated, directly, on the torture and forced disappearance of the regime's political opposition; he was, also, the founder of the White Squad: a paramilitary organization which was in charge of finishing the urban guerrilla. The article enquires how Nazar Haro took part on the Mexican State's struggle against the revolutionary violence, attending the ideological atmosphere which was justified the state violence and its mechanism of repression.
\end{abstract}

Key words: Mexico; Miguel Nazar Haro, dirty war, contra insurgency, tortureMiguel Nazar Haro and the dirty war in Mexico

Licenciado en Estudios Latinoamericanos por parte de la Universidad Nacional Autónoma de México (UNAM). Actualmente adelanta una Maestría en Estudios Latinoamericanos en la Universidad Nacional Autónoma de México. Dirección electrónica: ferlo8990@hotmail.com 


\section{Miguel Nazar Haro e a guerra suja no México}

\section{Resumo}

Miguel Nazar Haro é lembrado como um dos principais executores da guerra suja no México entre as décadas de 1960 e 1980. Participante direto na tortura e desaparecimento dos opositores políticos do regime, foi também o fundador da Brigada Blanca, organização paramilitar encarregada de aniquilar à guerrilha urbana. $\bigcirc$ presente artigo indaga como Nazar Haro participou da luta do Estado mexicano contra a violência revolucionária, atendendo ao ambiente ideológico que justificou a violência estatal e seus mecanismos de repressão.

Palavras chave: México, Miguel Nazar Haro, guerra suja, contrarrevolução, tortura

\section{Introducción}

Hombre de pocas palabras y de escaso perfil público, Miguel Nazar Haro es una de las figuras más representativas de la guerra sucia en México, nombre con el que se le conoce a las prácticas extrajudiciales que el Estado dispuso para el aniquilamiento de la oposición al régimen, particularmente la armada, entre las décadas de 1960 y 1980. Pese a la centralidad del personaje dentro de este proceso oscuro de la historia mexicana, son escasos los trabajos académicos que aborden sus acciones como parte de un complejo entramado gubernamental que, mediante el uso del terror, cometió crímenes de lesa humanidad, cuyas heridas aún se mantienen abiertas. Por ende, el presente artículo busca recuperar el papel que jugó Nazar Haro, también conocido como El Tigre por sus allegados y víctimas, en la guerra sucia, atendiendo el ambiente ideológico que justificó la violencia estatal y los principales aportes del personaje en los mecanismos de represión.

Para tal cometido, el texto se divide en tres partes. En la primera se presenta el contexto histórico y las características principales de la guerra sucia, reflexionando acerca de la importancia del papel de México dentro del desarrollo de los terrorismos de Estado latinoamericanos. El segundo apartado se centra en la participación de Nazar Haro en la guerra sucia, recuperando los elementos más importantes de la misma, entre ellos su crueldad, su fascinación por la tortura y su liderazgo en el aniquilamiento de la guerrilla urbana, que lo llevó a crear la Brigada Blanca, grupo paramilitar que fungió como escuadrón de la muerte. Por último, se plantea un breve epílogo sobre la impunidad con la que Nazar Haro vivió sus últimos años, reflexionando sobre la necesidad urgente de que los crímenes políticos del pasado no sean olvidados. 


\section{Aspectos generales de la guerra sucia en México}

Durante las décadas de 1960 y 1970 México vivió la aparición de diversos grupos guerrilleros que buscaron transformar la realidad política y socioeconómica del país a través de la violencia revolucionaria, entendida como las acciones armadas que poseen un tinte político y están encaminadas contra un régimen considerado opresor y autoritario. La aparición de las guerrillas fue el resultado de la cerrazón política del Estado mexicano a todo tipo de oposición, reprimiendo con brutalidad toda muestra de descontento social. Esta situación provocó la radicalización de diversos sectores de la sociedad, entre ellos los estudiantes y varios miembros de estrato medio del clero, quienes adoptaron un discurso revolucionario que justificó la lucha armada a partir de la noción de que los cambios que deseaban no podrían obtenerse por mecanismos y procedimientos legales, siendo las armas la última opción que el poder les dejaba al no existir espacios de acción y representación posibles. Se considera que alrededor de 1860 hombres y mujeres tomaron las armas durante estos años, creando 29 organizaciones diferentes, ${ }^{2}$ entre ellas el Partido de los Pobres (PDLP), encabezado por el maestro Lucio Cabañas, el Movimiento de Acción Revolucionaria (MAR) y la Liga Comunista 23 de Septiembre (LC23S).

El panorama internacional fortaleció la convicción de los jóvenes mexicanos que optaron por la lucha armada. En el caso concreto de América Latina, el triunfo de la Revolución Cubana en 1959 marcó fuertemente la creencia de que mediante las armas se transformaría inevitablemente el sistema político oligarca y represor que imperaba en los países de la región. Varios movimientos armados que serán actores clave en la vida política de sus respectivos países nacieron bajo este ambiente revolucionario, entre ellos el Frente Sandinista de Liberación Nacional (FSLN) en Nicaragua ( 196 I) y el Movimiento de Liberación Nacional-Tupamaros (MLN-T) en Uruguay ( 1965). Algunos guerrilleros se convirtieron en un modelo a seguir por quienes aspiraban a un mundo nuevo y una sociedad más justa, entre ellos el médico argentino Ernesto "Che" Guevara y el cura colombiano Camilo Torres. Para muchos de los futuros guerrilleros, México no podía permanecer ajeno a esta emergencia de la violencia revolucionaria en el continente. Fernando Pineda Ochoa, ex integrante del $\mathrm{MAR}^{3}$, señala al respecto lo siguiente: "Dentro de este contexto, la gesta cubana se convirtió en un ejemplo de consecuencias impredecibles. Surgieron los libros y los folletos que avalaban la guerra de guerrillas y los 'focos' guerrilleros aparecieron como hongos de Centro a Sudamérica, en selvas, serranías y ciudades del continente americano. ¿Por qué México iba a ser la excepción, si las similitudes abundaban?"'4

2 Aguayo Quezada, Sergio. La charola. Una historia de los servicios de inteligencia en México. México, D.F.: Grijalbo, 200 I, pág. I 19.

3 El Movimiento de Acción Revolucionaria (MAR) nació en 1969 en la ciudad de Moscú. Fue conformado por un grupo de becarios que se encontraban estudiando en la Universidad Patricio Lumumba, conocida por recibir a estudiantes provenientes de diversos países del Tercer Mundo. Sus integrantes se entrenaron militarmente en Corea del Norte, siendo el único caso en el que una guerrilla mexicana contó con apoyo internacional. Fue el primer grupo armado que actuó en las ciudades. Conforme la represión gubernamental le fue asestando golpes cada vez más contundentes, el MAR decidió priorizar el trabajo político de masas en lugar de las acciones militares, las cuales duraron hasta 1979.

4 Pineda Ochoa, Fernando. En las profundidades del mar (El oro no llegó de Moscú). México, D.F.: Plaza y Valdés, 2003, pág. 224. 
Ante la creciente oleada y accionar de las guerrillas, el Estado mexicano reaccionó con una violencia cruenta y eficaz, la cual se expandió contra toda señal de protesta social. Se conoce como guerra sucia a la serie de prácticas encaminadas al aniquilamiento de las guerrillas, las cuales fueron de carácter extrajudicial al rebasar los límites de la legalidad. Entre estas prácticas puede mencionarse las detenciones ilegales, las cárceles clandestinas, las torturas, los asesinatos a sangre fría y las desapariciones forzadas de las que fueron víctimas los guerrilleros y, en algunos casos, sus familiares y amigos. La guerra sucia se caracteriza por violar la propia ley que se dice defender, proviniendo dicha violación desde el propio Estado. ${ }^{5}$ No se aplican mecanismos legales para acabar con la guerriIla, sino que estos se quebrantan para proceder con el exterminio de los movimientos armados, lo que a su vez garantiza la impunidad de los perpetradores, ya que sus actos son una burla a la justicia. La represión se convirtió en la única política gubernamental efectiva. Se calcula que más de tres mil personas asociadas a la guerrilla murieron y más de quinientas se encuentran desaparecidas.

La lógica con la que se gestaron los procesos de aniquilamiento de la guerra sucia estuvo influida por la Doctrina de Seguridad Nacional (DSN), desarrollada por los Estados Unidos a partir de la lucha contra el comunismo en América Latina, región visualizada como un escenario privilegiado en dicha tarea durante la Guerra Fría. La DSN planteaba que la integridad y soberanía de los países latinoamericanos se encontraban amenazadas por la existencia de un "enemigo político interno", el cual debía de combatirse hasta ser destruido. A partir de dicho postulado, las Fuerzas Armadas y demás instituciones y organismos de seguridad reconfiguraron su tarea de defender las fronteras nacionales contra un agente externo y se abocaron a reprimir a los sectores políticos y sociales opositores, acusados de formar parte de una conspiración promovida por la Unión Soviética, cuyo objetivo era permitir la avanzada del comunismo mediante el debilitamiento del orden interno, de la seguridad nacional.

El régimen autoritario mexicano se adscribió a la DSN, alineándose a Estados Unidos en su combate al comunismo, el cual se reprodujo al interior del país bajo la forma de la subversión. Lo anterior no significa que México no haya tenido encuentros conflictivos con el vecino del norte, ya que siempre intentó mantener un margen de independencia en diversos temas, como lo fue el de la política exterior, siendo el único país, por ejemplo, que votó contra la expulsión de Cuba de la Organización de Estados Americanos (OEA) en 1962. ${ }^{6}$

Por su parte, el discurso ideológico del nacionalismo posrevolucionario mexicano, que se presentaba como una tercera vía entre capitalismo y socialismo, nunca fue del agrado de Estados Unidos, ya que contrariaba varios de sus intereses comerciales. Peor aún, toda forma de nacionalismo le parecía

5 Mendoza García, Jorge. "La tortura en el marco de la guerra sucia en México". Polis, Volumen 7, Número 2 (20I I): pág. I49.

6 Junto al rechazo a la resolución de la OEA, México fue el único país latinoamericano que nunca rompió relaciones diplomáticas con el régimen cubano. Esta situación afianzó los lazos de amistad entre los dos países, a pesar de las diferencias ideológicas. Como respuesta solidaria al apoyo brindado por México, Fidel Castro no intervino en la política interna del país, ni apoyó la formación de focos guerrilleros, a diferencia de lo ocurrido en otros países como Colombia con el Ejército de Liberación Nacional (ELN) y de Venezuela con las Fuerzas Armadas de Liberación Nacional (FALN). La decisión de Castro fue contraproducente para las guerrillas mexicanas, ya que las aisló internacionalmente, limitando sus márgenes de maniobra y acción. 
repulsiva al gobierno de Washington, ya que temía que éste se radicalizara y deviniera en proyectos como el socialista cubano. Sin embargo, el tenso ambiente de la Guerra Fría y la radicalización de la oposición al régimen provocaron que el nacionalismo mexicano se reconfigurara, principalmente a raíz de la DSN, de tal forma que toda muestra de descontento fuera adjudicada a una conspiración comunista internacional, discurso que justificaba la represión estatal bajo el argumento de defender la integridad de la nación. A esta lógica se adscribieron dos de los principales autores intelectuales de la guerra sucia: los presidentes Gustavo Díaz Ordaz (1964-1970) y Luis Echeverría Álvarez (19701976). El nuevo panorama ideológico permitió el entendimiento entre los gobiernos de México y Estados Unidos, cuya relación puede resumirse en un discurso que Díaz Ordaz realizó en 1967 ante el Congreso del país vecino:

La geografía nos hizo vecinos, la economía nos ha convertido en clientes de los mejores, y la decidida voluntad de nuestros pueblos, superando en ocasiones el curso inexorable de la historia, nos ha hecho cordiales y respetuosos amigos. Nuestros tratos deben corresponder siempre a esas calidades: de vecinos, buenos vecinos; de clientes, magníficos clientes; de amigos, leales amigos.?

En nombre del combate contra el comunismo, Estados Unidos reforzó sus relaciones con las Fuerzas Armadas y los organismos de seguridad nacionales. Oficiales estadounidenses adoctrinaron a los militares mexicanos en contrainsurgencia, inteligencia militar, guerra psicológica y procedimientos de tortura para obtención de información por parte del enemigo. Con el objetivo de profesionalizar al Ejército mexicano en el combate a la guerrilla, para 1968 Díaz Ordaz envió a 306 oficiales a las academias militares estadounidenses, entre ellas la Escuela de las Américas. ${ }^{8}$ También la Agencia Central de Inteligencia (CIA) y el Buró Federal de Investigación (FBI) ayudaron a formar técnica e ideológicamente a sus contrapartes, principalmente a los integrantes de la Dirección Federal de Seguridad (DFS), ${ }^{9}$ principal organismo de seguridad e inteligencia que se encargó de la guerra sucia en las principales ciudades del país. Varios de los militares y policías entrenados por Estados Unidos se convirtieron en los futuros represores de la guerra sucia. Entre ellos se encontraba Nazar Haro.

7 Citado en Condés Lara, Enrique. Represión y rebelión en México (1959-1985). Tomo I. México, D.F.: Miguel Ángel Porrúa, Benemérita Universidad Autónoma de Puebla, 2007, pág. 63.

8 Sierra, Jorge Luis. "Fuerzas armadas y contrainsurgencia (1965-1982)" en Movimientos armados en México, siglo XX. Verónica Oikión Solano y Marta Eugenia García Ugarte (editoras). Zamora, Michoacán: El Colegio de Michoacán, Centro de Investigaciones y Estudios Superiores en Antropología Social, 2008, pág. 375.

9 La DFS se creó en 1947 con asesoría del FBI. Estaba conformada por militares y policías de élite que en sus inicios dependieron directamente de la Presidencia de la República. Posteriormente pasaron a estar bajo las órdenes de la Secretaría de Gobernación. Esta fuerte vinculación con las máximas autoridades políticas del país le permitió a la DFS actuar con total impunidad a lo largo de su existencia. Una de sus funciones principales fue el espionaje, la infiltración y el acoso de opositores y de miembros del propio régimen. Durante los años de la guerra sucia, la DFS se hizo famosa por las torturas y las violaciones a los derechos humanos que cometió contra los detenidos acusados de ser subversivos. La práctica aniquilación de los grupos armados a mediados de la década de 1980 y la mala fama que poseía la institución llevaron a que se decretara su desaparición en 1985. En lugar de la DFS se creó la Dirección General de Investigación y Seguridad Nacional, predecesora del actual Centro de Investigación y Seguridad Nacional (CISEN). 
Acorde con Jorge Luis Sierra, algunos de los principios de la contrainsurgencia que operó en la guerra sucia fueron los siguientes: contención y aniquilamiento de los grupos armados, la descalificación de las guerrillas al considerarlos simples delincuentes para justificar la represión en su contra, la modernización del armamento de las Fuerzas Armadas, las prácticas extrajudiciales como la tortura y la desaparición forzada, junto a la organización de grupos paramilitares que contaron con el aval del Estado para actuar con impunidad. ${ }^{10}$ La guerra sucia contra la guerrilla se desenvolvió en dos entornos: el rural y el urbano. En el primero, el Ejército mexicano se encargó de combatir a la guerrilla rural y a los sectores sociales que la apoyaron. El caso que mejor muestra lo anterior es el aniquilamiento del PDLP en el estado de Guerrero." En el espacio urbano, los organismos policiales fueron los principales encargados de combatir a las guerrillas urbanas que surgieron a raíz de la radicalización de los jóvenes tras la represión que sufrieron los movimientos estudiantiles de 1968 y 1971. En este ambiente fue en donde se desenvolvió el accionar represivo de Nazar Haro y de uno de los grupos paramilitares más conocidos de la guerra sucia, creado a instancia suya: la Brigada Blanca.

Las características señaladas en torno a la guerra sucia en México son centrales para replantearnos el papel de este país en los terrorismos de Estado que se desarrollaron en América Latina. Pese a la fachada democrática que ostentó el país ante el extranjero, el comportamiento interno del sistema político mexicano fue vertical y autoritario, a semejanza de sus pares sudamericanos gobernados por dictaduras. La temprana aparición de los mecanismos de represión en México, a mediados de los años sesenta del siglo pasado, marcó un antecedente importante para los canales represivos que se desarrollaron en los setenta en el Cono Sur. En este sentido, México más que emular dio cátedra de metodologías y prácticas eficaces de aniquilamiento de una parte de su población. Por mencionar un ejemplo concreto, México tiene el indigno honor de ser el primer país latinoamericano en poner en práctica los "vuelos de la muerte" para desaparecer a los disidentes políticos. ${ }^{12}$

10 Sierra, Jorge Luis, op. cit., págs. 361-362.

II El Partido de los Pobres fue una organización político militar fundada por el maestro Lucio Cabañas Barrientos. Su origen se encuentra en el actuar represivo del gobierno estatal de Guerrero ante las demandas campesinas y magisteriales. El I 8 de mayo de 1967, la policía masacró al I personas en el municipio de Atoyac de Álvarez, durante un mitin en una escuela primaria y en el cual participaba Cabañas. Al ser acusado por el gobierno de ser el responsable de la masacre, Cabañas huye y se refugia en las montañas, en donde funda el PDLP. Su brazo armado fue la Brigada Campesina de Ajusticiamiento (BCA). La guerrilla tuvo el apoyo de varias comunidades campesinas de la sierra, por lo que en el accionar contrainsurgente se volvió prioridad no sólo atacar al grupo armado sino también a los civiles que los ayudaban. Entre 1967 y 197I, el PDLP mantuvo en jaque a las fuerzas gubernamentales, asestándoles varios golpes mediante emboscadas, lo que ocasionó la saturación militar del Estado. El principal golpe que dio la organización ocurrió el 30 de mayo de 1974, cuando fue secuestrado el candidato a gobernador estatal Rubén Figueroa, quien permaneció privado de su libertad hasta el 8 de septiembre de ese año, cuando es liberado tras un enfrentamiento con el Ejército. Los constantes golpes de la contrainsurgencia obligaron a Cabañas y al PDLP a aislarse cada vez más de su base social, la cual fue víctima del operar de la guerra sucia en Guerrero, caracterizada por el arrasamiento de comunidades enteras y por las desapariciones forzadas. Debilitado y aislado, Cabañas fue ejecutado el 2 de diciembre de 1974 cerca de la localidad de Tecpan. Varios sobrevivientes del PDLP se mantuvieron alzados tras la muerte de Cabañas y en 1982 se fusionaron con el Partido Revolucionario Obrero Clandestino Unión del Pueblo (PROCUP). A esta fusión se le agregaron la de más de una decena de organizaciones armadas menores y el 18 de mayo de 1994 se constituyó el Ejército Popular Revolucionario (EPR), actualmente la principal guerrilla que pervive en México.

12 Los "vuelos de la muerte" fueron una de las prácticas de aniquilamiento más atroces que desarrolló la guerra sucia en Guerrero a partir de 1975. Los encargados de realizarla fueron el entonces mayor Mario Arturo Acosta Chaparro y el teniente coronel 
Los abusos cometidos durante la guerra sucia no sólo afectaron a la sociedad mexicana, también los exiliados latinoamericanos fueron víctimas de la vigilancia y el hostigamiento de las fuerzas de seguridad. Lo anterior fue resultado de la desconfianza que los refugiados y los perseguidos políticos les ocasionaron a estos organismos, para quienes nunca existió la famosa solidaridad del asilo político mexicano. En algunos casos, sin tener la estructura y la organización del Plan Cóndor, las autoridades mexicanas trabajaron con sus pares de otros países para perseguir a los opositores políticos. Tal fue el caso de la cooperación que existió con los gobiernos militares guatemaltecos para reprimir a los disidentes y guerrilleros que se acercaban a la frontera en busca de ayuda, relación estratégica que duró cerca de dos décadas a partir de 1961, año en el que el presidente guatemalteco Ydígoras Fuentes (1958-1963) le pidió expresa ayuda para combatir a la subversión a su par mexicano Adolfo López Mateos (1958-1964). Gracias al intercambio de información entre México y Guatemala, en donde intervino Estados Unidos en varias ocasiones, cientos de guatemaltecos fueron víctimas de las dictaduras militares del país centroamericano, sufriendo la prisión, la desaparición forzada, la tortura y la muerte. ${ }^{13}$

Los argumentos señalados permiten concluir que México compartió características comunes con el resto de Latinoamérica en torno a los modos con los que se planteó transformar a las sociedades a través del uso del terror. Lo anterior no significa que los impactos de la represión fueran de la misma magnitud en cada una de las sociedades latinoamericanas, ya que mientras países como Brasil, Uruguay y Honduras vivieron una represión feroz, pero limitada a pequeños sectores de la población, casos como los de Colombia y Argentina, con decenas de miles de asesinatos, son indicativos de una represión que atravesó todo el tejido social. ${ }^{14}$ En el caso concreto de la guerra sucia mexicana, si bien todo parece señalar que la represión fue específica contra determinados actores sociales, como

Francisco Quirós Hermosillo, quienes instruyeron a sus subordinados en cómo proceder con las ejecuciones de sus víctimas para posteriormente arrojarlas al mar. Este procedimiento se conoce en gran medida gracias al testimonio de Margarito Monroy Candia, en ese entonces capitán segundo de la Fuerza Aérea Mexicana, quien era el responsable de dar mantenimiento a las aeronaves que se utilizaron en los vuelos, llegando él a tripular algunos. Acorde a sus declaraciones, los detenidos, en su mayoría humildes campesinos, eran sentados en un banquito, se les vendaba los ojos y se les ejecutaba con un balazo en la nuca. El propio Quirós Hermosillo se encargó de jalar el gatillo en varias ocasiones. Después los cuerpos eran subidos al avión, algunos de ellos todavía agónicos. Los "vuelos de la muerte" partían de la Base Aérea Militar Número 7, ubicada cerca del puerto de Acapulco. En su testimonio, Monroy Candia indicó haber asistido personalmente a unos quince viajes, en los cuales fueron arrojados al mar entre 120 y 150 cuerpos, algunos de ellos dentro de costales rellenados con piedras para que se hundieran. [Castellanos, Laura. México armado 1943-1981. México, D.F.: Ediciones Era, 201 I, págs. 160-163.]

13 Los refugiados guatemaltecos fueron víctimas del espionaje de las policías mexicanas, incluidas figuras de renombre como el escritor Luis Cardoza y Aragón y el ex presidente derrocado Jacobo Arbenz. En 1966 se logró desmantelar un organismo de las Fuerzas Armadas Rebeldes (FAR) establecido en el país y en mayo de 1970 cayó muerto por tropas mexicanas Marco Antonio Yon Sosa "El Chino", líder guerrillero del Movimiento Revolucionario 13 de Noviembre (MR- I3). Los mexicanos que ayudaron a la guerrilla guatemalteca corrieron con la misma suerte, como fueron los casos de David Aguilar Mora y Eunice Campirán Villicaña, torturados y ejecutados por tropas guatemaltecas junto con algunos dirigentes del Partido Guatemalteco del Trabajo (PGT) y del MR-13. El gobierno mexicano estuvo al tanto del caso desde el momento en que Aguilar Mora fue detenido, pero prefirió mostrar desconocimiento ante el caso y permitir su ejecución. [Condés Lara, Enrique, op. cit., págs. 72-77.]

I4 Feierstein, Daniel. "Guerra, genocidio, violencia política y sistema concentracionario en América Latina" en Terrorismo de Estado y genocidio en América Latina. Daniel Feierstein (compilador). Buenos Aires: Prometeo Libros, Programa Naciones Unidas para el Desarrollo, 2009, pág. 20. 
las guerrillas y sus bases de apoyo, aún falta mucho por ahondar en este tema, que la historia oficial ha intentado ocultar ante la sociedad. El investigar la figura represiva de Miguel Nazar Haro, como una especie de microcosmos de lo que ocurrió en aquellas décadas, es un intento de recuperar la memoria colectiva y evitar el olvido de los crímenes del pasado.

\section{Miguel Nazar Haro y su participación en la guerra sucia}

Hijo de inmigrantes libaneses, Miguel Nazar Haro nació el 26 de septiembre de 1924 en la ciudad de Pánuco, Veracruz. En 1950 fue aceptado en el Servicio Secreto mexicano como patrullero. Diez años después, el 16 de febrero de 1960, ingresó a la DFS, haciéndose cargo de la guardia de la institución. La extrema obediencia a sus superiores y el cumplimiento de todas las tareas que le eran dadas le permitió ascender rápidamente. En 1965 lo ascendieron a jefe de grupo y como premio el presidente Gustavo Díaz Ordaz lo mandó becado a Washington a estudiar en la Academia Internacional de Policía. Durante su estancia de seis meses se formó en el anticomunismo y se especializó en labores de contrainsurgencia y subversión, mientras en México el 23 de septiembre acontecía el asalto al cuartel militar de Madera, Chihuahua, acontecimiento considerado como la primera acción de la guerrilla contemporánea en este país. Tiempo después, Nazar comentó sobre su curso en Washington que "estudié las diferencias ideológicas entre capitalismo y comunismo; estaba consciente de la intervención del comunismo internacional en los países de Centroamérica". ${ }^{5}$

Terminada su estancia en Estados Unidos, Nazar Haro se reincorporó a la DFS. El titular de este organismo bajo el gobierno de Díaz Ordaz, Fernando Gutiérrez Barrios, ya tenía planeado utilizar lo aprendido por el veracruzano. El asalto al cuartel Madera agarró por sorpresa a los servicios de inteligencia y de seguridad interna del Estado, por lo que se volvió primordial la creación de un grupo especializado en el combate a las guerrillas. Nazar Haro fue el hombre elegido para dicha tarea. En noviembre de 1965 fundó el ultra secreto Grupo de Investigaciones Especiales C-047, vanguardia en las operaciones destinadas a infiltrar a los enemigos del régimen. Muy pronto sus actividades rindieron frutos al desmantelar al Movimiento Revolucionario del Pueblo (MRP), organización guerrillera que se encontraba en plena formación y a la que la DFS infiltró a uno de sus agentes, lo que permitió la captura de sus dirigentes, entre ellos el periodista Víctor Rico Galán.

El combate a la guerrilla estaba plenamente justificado. Para Nazar Haro, los guerrilleros eran simples delincuentes, "aventureros que querían alcanzar el poder". Gracias a esta retórica discursiva, que reprodujeron tantos otros policías como militares, a los movimientos armados se les negó su estatus de actores políticos y el Estado mexicano legitimó su aniquilamiento ante la sociedad en vez de atender las causas de fondo que provocaron su aparición. En una entrevista otorgada en 2003 al diario La Jornada, Nazar Haro fue más allá en su visión parcializada de la guerrilla, acusándola de ser la principal responsable de los altos índices de delincuencia que el país vive a partir de entonces: "No había la delincuencia que hay ahora, hasta que surgieron estos señores entrenados en Corea del

15 Citado en Torres, Jorge. Nazar, la historia secreta. El hombre detrás de la guerra sucia. México, D.F.: Debate, 2008, pág. 26. 
Norte [en referencia al MAR] que, inspirados por aventuras guerrilleras de otros países, buscaron el poder. [...] Pusieron bombas, perpetraron secuestros, asaltaron bancos, mataron policías con alevosía y ventaja. Todo con una bandera de guerrilleros". ${ }^{6}$

Una práctica común de las Fuerzas Armadas y los servicios de inteligencia mexicanos fue sobredimensionar la amenaza guerrillera como un peligro serio para la estabilidad nacional, con la doble intención de obtener mayores recursos económicos y de poder actuar con total impunidad. Ante la pregunta, realizada en la entrevista ya citada, sobre si la guerrilla había sido una amenaza seria y real al poder político mexicano, Nazar Haro contestó un "claro que sî", agregando que "eran organizaciones que ponían bombas en Gobernación, en la Confederación de Trabajadores de México, en Televisa, en el PRI, en diferentes delegaciones. Quisieron hacer entender en otros países que el movimiento estudiantil era una revolución en México, y entonces se expuso el prestigio de nuestro país en el extranjero".'17

De la cita anterior se desprende que el combate a la subversión significó para Nazar Haro luchar por una causa sagrada: la nación. En esta lógica, el anticomunismo de las autoridades mexicanas, que a la larga permeó en el tejido del sector más conservador de la sociedad, se presentó como una defensa del nacionalismo revolucionario, proyecto que en la década de 1960 comenzó a debilitarse ante los crecientes cuestionamientos del rumbo vertical y autoritario que adquirió la Revolución institucionalizada. Sin embargo, Nazar Haro consideró que nunca existió la cerrazón política del Estado mexicano, ya que México "es un país de libertades" y "digno de defenderlo hasta con la vida", según declaró al diario El Universal en 2003. Para él no existieron motivos locales que justificaran la aparición ni las críticas al gobierno por parte de los movimientos sociales de la época, incluidas las guerrillas, todos ellos resultado de una conspiración soviética internacional, enfocada en "infiltrar, lavar cerebros a jóvenes nacionales para agitar su país de origen y poderlos atraer hacia ellos". ${ }^{8}$ De esta manera, en medio del ambiente beligerante de la Guerra Fría, se articuló la DSN y el combate al enemigo interno en las fuerzas de seguridad mexicana y sus principales figuras.

El miedo ante la pérdida del consenso social justificó la paranoia gubernamental y de los sectores sociales conservadores. Esta situación bajó los niveles de tolerancia a la represión y la muerte, lo que facilitó el desarrollo de los mecanismos de aniquilamiento de la guerra sucia bajo el argumento de combatir el anticomunismo. El combate al "enemigo interno" se facilitó por la evidente y sincera paranoia anticomunista que tenía el presidente Díaz Ordaz, alimentada deliberadamente por Nazar Haro y otros de sus colaboradores en el área de seguridad, ya fuera porque la compartían o porque así le convenía a sus intereses. La DFS resultó beneficiada de las paranoias del presidente, ya que siempre sobredimensionaron la fuerza real de las guerrillas para poder incrementar su poder, ya que

I6 Citado en Castillo García, Gustavo. "Los guerrilleros, aventureros que querían el poder". La Jornada, Distrito Federal, miércoles 5 de febrero de 2003, pág. 18.

17 lbídem.

I8 Citado en "Especial Nazar Haro, un tigre que murió en su propia jaula". El Universal, sábado 28 de enero de 20 I2. Disponible en: <http://www.eluniversal.com.mx/notas/825789.html> (6 de mayo de 20 I3). 
un enemigo fuerte significaba mejores presupuestos, mayor capacidad operativa y un aval total a la impunidad de sus crímenes. ${ }^{19}$

Además del combate inicial a las guerrillas con el Grupo de Investigaciones Especiales C-047, Nazar Haro participó en la reacción conservadora contra el movimiento estudiantil de 1968. Se le encomendó la localización de armas en la Ciudad Universitaria de la Universidad Nacional Autónoma de México (UNAM), tras ser intervenida por el Ejército el 18 de septiembre. De acuerdo al informe presentado por Gutiérrez Barrios a Díaz Ordaz, Nazar localizó algunas armas y cartuchos en la Facultad de Medicina, lugar donde estaba reunido el Consejo General de Huelga, órgano directriz del movimiento. Lo cierto es que el operativo militar movilizó a un total aproximado de 3000 hombres y sólo se hallaron siete armas y diecisiete cartuchos, ${ }^{20}$ muestra de los altos índices de paranoia que existían en contra de un movimiento cuya principal demanda era la apertura democrática del régimen.

Nazar también estuvo presente el 2 de octubre en la Plaza de las Tres Culturas en Tlatelolco, lugar en donde ocurrió la famosa masacre que desarticuló al movimiento estudiantil. Interesado en conocer los discursos estudiantiles, a su juicio caldos de cultivo para la insurgencia, ${ }^{21}$ decidió visitar la plaza ese día, hasta que los disparos lanzados por los militares lo obligaron a huir del lugar para proteger su vida. El modo brutal con el que fue sofocado el movimiento generó en los jóvenes el factor subjetivo de que únicamente las armas y la violencia revolucionaria lograrían cambiar el ambiente represivo que se vivía en el país, naciendo a raíz de ello el fenómeno de las guerrillas urbanas, cuya persecución convirtió a Nazar en uno de los principales ejecutores de la guerra sucia.

El I de diciembre de 1970 Luis Echeverría Álvarez asume como presidente de la República. Con su llegada se realizaron cambios al interior de la DFS. El capitán Luis de la Barreda Moreno fue elegido director del organismo mientras que Nazar Haro ocupó el cargo de subdirector. Se considera que a pesar de ser el segundo al mando, El Tigre ejerció un poder mayor al de su superior, ya que gracias a él la DFS se convirtió en la principal institución que participó en la lucha contrainsurgente, gracias a que coordinaba operativos con otras fuerzas de seguridad y proporcionaba la mayor parte de la información en torno al rastreo y aniquilamiento de los guerrilleros. En 1981, durante una recepción a importantes funcionarios del gobierno en las instalaciones centrales de la DFS, Nazar recibió los siguientes elogios, indicativos de su importancia dentro de la preservación del orden hegemónico:

Desde 1970 y hasta 1978 [Nazar Haro] desempeñó el cargo de subdirector general y se caracterizó por su actuación en contra de los grupos subversivos... y principalmente en el golpe directo en contra de una organización clandestina llamada Liga Comunista 23 de Septiembre que intentó el derrocamiento del gobierno mexicano. Después de haber participado en múltiples acciones, en un lapso de seis

19 Aguayo Quezada, Sergio, op. cit., págs. 123-124.

20 Scherer García, Julio. "Los patriotas. De Tlatelolco a la guerra sucia” en Los patriotas. De Tlatelolco a la guerra sucia. México, D.F.: Aguilar, 2004, pág. 14.

21 Torres, Jorge, op. cit., pág. 31. 
años dio por terminada su campaña en contra de ese grupo con la satisfacción de haber logrado su exterminio. ${ }^{22}$

Como menciona la cita anterior, uno de los objetivos centrales de Nazar Haro fue aniquilar a la Liga Comunista 23 de Septiembre (LC23S), la principal guerrilla urbana que existió en México. Para el subdirector de la DFS, la Liga representó una seria amenaza para la seguridad nacional al estar conformada por "más de 700 jóvenes armados y fanáticamente preparados". ${ }^{23}$ Sin embargo, los mecanismos brutales de exterminio que operaron contra la Liga fueron la culminación de todo el proceso de contrainsurgencia y acostumbramiento a la muerte que se pusieron en práctica con los grupos armados que aparecieron antes, entre ellos el MAR.

Una de las principales características de Nazar Haro fue su personalidad psicópata, que tenía el gusto por la tortura y por provocar dolor en el enemigo el mayor tiempo posible. La tortura es un ejercicio de violencia milenario, utilizado durante la guerra sucia por el poder para escarmentar todo tipo de disidencia. La tortura tiene como objetivos el aislamiento social del torturado, la humillación, la presión psicológica, el dolor físico y, de ser posible, la intimidación de familiares y amigos; en pocas palabras, inculcar miedo. ${ }^{24} \mathrm{El}$ fin último de la tortura es someter la voluntad del otro a partir de un ejercicio de poder, violentar su espacio interior para mostrar al torturado que no es libre, que depende del torturador para seguir vivo, hasta que finalmente se pierde la voluntad de vivir. Este aspecto oscuro de Nazar Haro se conoce gracias a los testimonios de varios ex guerrilleros que aseguraron haber sido torturados personalmente por él, entre ellos Fernando Pineda Ochoa, quien atestiguó haber visto los contrastantes cambios de ánimo del policía mientras torturaba, quien "a veces parecía loco furioso, a veces desbordaba euforia". 25

De hecho, el MAR fue descubierto por Nazar Haro gracias a la tortura. Pineda Ochoa y varios de sus compañeros cayeron en sus manos a inicios de 1971, bajo la sospecha de pertenecer a una célula guerrillera, sin saber exactamente a cuál. Las torturas iniciales incluían descargas eléctricas en testículos para los hombres y en senos y vagina para las mujeres. Una de sus compañeras detenidas, Ana María Tecla, se encuentra actualmente desaparecida. Otro de los detenidos era Fabrizio Gómez Souza, comandante general del MAR, cuya captura le permitió a los policías confirmar la existencia del grupo armado. Después de un mes de torturas, Nazar descubrió el entrenamiento militar que el MAR realizó en Corea del Norte. En una ocasión, se le presentó furibundo a Pineda Ochoa exigiéndole que le dijera todo lo que sabía al respecto, jalándose los ojos para parecer oriental. Conforme pasaban los días aumentaba la saña de sus captores, quienes los atormentaban con falsas ejecuciones y con la dinámica del policía bueno y el malo, mientras se continuaba con los golpes y el uso de la

22 Citado en Aguayo Quezada, Sergio, op. cit., pág. 182.

23 Citado en Castillo García, Gustavo. "Comunismo, una amenaza para el país; tenía 700 jóvenes armados: Nazar Haro". La Jornada, Distrito Federal, domingo 27 de enero de 2013, pág. 15.

24 Mendoza García, Jorge, op. cit., págs. I53- 154.

25 Citado en Petrich, Blanche. "Nazar enloquecía cuando torturaba, narra un ex integrante del MAR". La Jornada, Distrito Federal, domingo 9 de febrero de 2003, pág. 10. 
picana. Después de cuarenta días, Pineda Ochoa corrió con la suerte de ser liberado. Entre febrero y marzo de 1971, fueron detenidos 19 guerrilleros del MAR, todos ellos víctimas de Nazar Haro, quien se convirtió en una leyenda dentro de las fuerzas de seguridad mexicanas, por lo que se le encargó la tarea de aniquilar a los subversivos a toda costa. ${ }^{26}$ La LC23S será la principal víctima de este recrudecimiento del ambiente represivo en las ciudades.

La LC23S nació en abril de 1973 en la ciudad de Guadalajara, Jalisco. Fue el resultado de la unión de varios grupos que realizaban operaciones político-militares a lo largo del país, entre los que destacaban Los Procesos de Nuevo León, Los Enfermos de Sinaloa, el Frente Estudiantil Revolucionario de Guadalajara, Los Lacandones del Distrito Federal y el Grupo Comunista Los Guajiros de Baja California. Desde sus orígenes, la Liga se consolidó como una organización guerrillera de alcance nacional, abarcando veinte Estados de la república. Entre 1973 y 1974 realizó varias operaciones que cuestionaron la eficacia de los servicios de inteligencia mexicanos por controlar a las guerrillas. El 17 de septiembre de 1973, un comando de la Liga realizó en Monterrey un intento fallido de secuestro que terminó en la muerte de Eugenio Garza Sada, uno de los empresarios más prominentes del país. El 10 de octubre, otro comando secuestró en Guadalajara al industrial Fernando Aranguren y al cónsul británico Duncan Williams, con la intención de ser intercambiados por los presos políticos. La negativa del gobierno a negociar significó la ejecución de Aranguren, mientras se decidió dejar en libertad a Williams. Finalmente, el 16 de enero de 1974 se puso en práctica el ensayo de la "insurrección general" en el valle de Culiacán, Sinaloa, donde miles de estudiantes y cerca de 10 mil obreros agrícolas realizaron un paro general.

La respuesta gubernamental a las acciones de la Liga buscó ser contundente, por lo que no se reparó en los mecanismos de aniquilamiento y de terror que se ejercieron contra el enemigo. Como menciona Jorge Luis Sierra, el combate contra la Liga marcó el inicio de una guerra total contra la guerrilla en México, ya que el gobierno decidió combatirla con todos los recursos posibles, aun cuando éstos pasaran por encima de las leyes y violaran la Constitución. En pocas palabras, había comenzado la fase más cruenta de la guerra sucia. ${ }^{27}$ Muestra de ello fue el sádico acto que protagonizaron Nazar Haro y la DFS como venganza por las muertes de Garza Sada y Aranguren. Efectivos del organismo de seguridad, comandados por El Tigre, localizaron y detuvieron a dos miembros importantes de la Liga: Ignacio Olivares y Salvador Corral, alias Sebas y Roberto respectivamente. Fueron brutalmente ejecutados. Gustavo Hirales, ex miembro de la Liga, describió de la siguiente manera la muerte de los dos guerrilleros:

Al Sebas le quebraron todos los huesos, le metieron clavos de viga en las rodillas, en los hombros; según la prensa, la causa de la muerte fue que le hicieron estallar el cráneo. Con Roberto hicieron otro tanto. Luego, en un acto ritual-satánico muy propio de la tira nassariana, a Sebas fueron a tirarlo a Guadalajara, cerca de la casa

26 Ibídem.

27 Sierra, Jorge Luis, op. cit., pág. 390. 
de los Aranguren, mientras que a Roberto lo aventaron en Monterrey, a unos metros de donde viven los Garza Lagüera. ${ }^{28}$

Pese a los terribles golpes que recibió la Liga entre 1973 y 1976, de los cuales destacan la desaparición de su fundador Ignacio Salas Obregón y del militante Jesús Piedra Ibarra, ${ }^{29}$ ésta se mantuvo en operaciones, intentando alimentar el trabajo político de masas ante la creciente militarización interna. Por su parte, Nazar Haro continuó comandando varios de los operativos en contra de la Liga. Una de las prácticas más recurrentes en las que incurrió fue sembrar la duda y la división interna dentro de la organización. Para ello, en ocasiones liberaba pronto a alguno de los detenidos o hablaba bien de un miembro de la Liga frente a sus compañeros torturados. Esta táctica psicológica surtió el efecto deseado. Temerosos de la existencia de infiltrados o de traidores a la causa, los cabecillas de la Liga procedieron al ajusticiamiento de varios de sus miembros, lo que ocasionó conflictos internos que la debilitaron con el transcurrir del tiempo.

En junio de 1976, Nazar Haro echó a andar el mecanismo ideal para el total aniquilamiento de la guerrilla en México. Su propuesta era crear un cuerpo de tareas especiales, conformado por miembros de todas las fuerzas de seguridad del país, cuya tarea central sería exterminar a todos los movimientos armados, principalmente a la LC23S. El 7 de junio, cerca de doscientos elementos de siete corporaciones policiaco-militares, entre ellas el Ejército y la DFS, fueron integrados a la Brigada Especial Antiguerrillas (BEA), con sede en el Campo Militar Número Uno (CMNU), uno de los principales centros clandestinos de detención, tortura y desaparición que operaron durante la guerra sucia. Los miembros de la BEA decidieron ponerle un nombre de guerra. Debido a que dentro de la Liga existía una Brigada Roja, color asociado al comunismo, entonces la BEA debía seleccionar un color que fuera su contraparte, asociado a la justa lucha contra la subversión. De esta manera nació

28 Hirales, Gustavo. Memoria de la guerra de los justos. México, D.F.: Cal y Arena, 1996, p. 7I.

29 El caso de Jesús Piedra Ibarra es relevante por las implicaciones que tuvo a posteriori en la lucha por la defensa de los derechos humanos y por la justicia a los crímenes cometidos durante la guerra sucia. Jesús fue detenido el I 8 de abril de 1975 en la ciudad de Monterrey por policías estatales, federales y militares coordinados por la DFS. Gracias a documentos gubernamentales y a testimonios de otros detenidos, se sabe que fue trasladado a la capital del país por órdenes de Nazar Haro, siendo retenido en el Campo Militar Número Uno, donde fue torturado. Después fue trasladado a diversas cárceles clandestinas, perdiéndose su rastro en 1984. La desaparición de Jesús llevó a su madre, Rosario Ibarra de Piedra, a iniciar un largo peregrinar en búsqueda de su paradero. Ante la negligencia gubernamental, Rosario Ibarra comenzó a relacionarse con otros familiares de desaparecidos políticos para conformar un frente común donde se presionara al Estado mexicano para que presentara la aparición con vida de sus familiares. Gracias a su iniciativa, en 1977 se crea el Comité Pro Defensa de Presos, Perseguidos, Desaparecidos y Exiliados Políticos, hoy denominado Comité Eureka, adquiriendo el apoyo inmediato de diversos sectores de la sociedad, entre ellos organizaciones estudiantiles y los partidos políticos de izquierda. Dos años después nació el Frente Nacional Contra la Represión (FNCR), organismo que aglutinó a 54 organizaciones de todo el país y que se convirtió en el gran antecedente en la lucha por los derechos humanos en México. La presión social, encabezada por las madres de los desaparecidos, obligó al gobierno de José López Portillo a comenzar a liberarlos. A partir de 1979, el Comité Eureka ha logrado la liberación de I 48 personas, si bien tiene registradas 557 desapariciones ocurridas durante la guerra sucia, número que se ha ido ampliando al involucrarse en otras causas sociales vinculadas a crímenes de Estado ocurridos tiempo después, como es el caso de la masacre de Acteal, ocurrida en el municipio de Chenalhó, Chiapas, el 22 de diciembre de 1997, cuando un comando paramilitar ejecutó a 45 indígenas, incluidos niños y ancianos, bajo la acusación infundada de ser colaboradores del Ejército Zapatista de Liberación Nacional (EZLN). Por su parte, Rosario Ibarra de Piedra se ha convertido hoy día en la figura más emblemática de la denuncia de los crímenes de la guerra sucia, siendo propuesta en varias ocasiones para el Premio Nobel de la Paz. 
formalmente la Brigada Blanca, escuadrón de la muerte cuya estructura administrativa y operativa fue encargada especialmente a Nazar Haro. ${ }^{30}$

La Brigada Blanca existió durante siete años (1976-1983), periodo en el cual sus integrantes fueron sometidos a un duro entrenamiento, consistente en el aprendizaje del pensamiento de la Liga, capacitación en el manejo de armas, combate físico, manejo de explosivos, técnicas de interrogatorio y de torturas, entre las que se encontraban terribles golpizas, los toques eléctricos, el "pocito" y el "pollo rostizado"." Los ataques sexuales contra las mujeres fueron frecuentes pero no constantes, ya que Nazar Haro buscaba evitar alguna especie de involucramiento sentimental que pudiera estorbar en las labores de aniquilamiento. La Brigada no redujo sus tareas a combatir a la guerrilla, ya que había que acabar con el mal de raíz, por lo que también se encargó de vigilar a los familiares y amigos de los detenidos-desaparecidos, a los movimientos sociales y a las figuras políticas de izquierda, es decir, todo elemento que fuera percibido como una amenaza al orden existente. En este sentido, como mencionó en una ocasión José Trinidad Gutiérrez Sánchez, ex director de la Policía Judicial del Distrito Federal (PJDF), una de las corporaciones que brindaron elementos a la organización paramilitar, "más que exterminar a las guerrillas, la Brigada Blanca terminó con el movimiento de insurrección y evitó una revuelta civil". 32

Mientras el escuadrón de la muerte mexicano se encargaba de poner en práctica la guerra sucia, José López Portillo asume como presidente de la república en diciembre de 1976, cargo que ocupó hasta 1982. Al igual que su predecesor, López Portillo realizó cambios al interior de la DFS. En marzo de 1977, Javier García Paniagua ocupa la dirección de la institución en lugar de Gutiérrez Barrios, mientras Nazar Haro permanece en la subdirección. Sin embargo, al año siguiente García Paniagua es nombrado subsecretario de Gobernación, situación que llevó a Nazar a ocupar el cargo titular de la institución. Bajo su administración de cuatro años (1978-1982), la DFS atravesó por un proceso de militarización caracterizado por la implementación de una disciplina sumamente estricta, que si se rompía implicaba severos castigos para los subordinados. Nazar también quiso adecuar las instalaciones de la DFS para exterminar por completo a la subversión. Gracias a un documento localizado en el Archivo General de la Nación (AGN), se sabe que en 1979 El Tigre solicitó la colocación de un incinerador dentro del edificio central de la DFS, lugar en el cual también se torturó y encerró ilegalmente a muchos guerrilleros. ${ }^{33}$ El objetivo, aparentemente claro, que iba a tener el incinerador,

30 Como menciona Laura Castellanos, Nazar Haro se convirtió en el jefe indiscutible de la Brigada Blanca debido a que "su telaraña de espionaje alcanzó a todas las instancias de seguridad y de gobierno [...], desde donde vigila, cruza datos, señala, captura, borra evidencias comprometedoras. Viaja a cualquier lugar del país donde hay una acción armada de envergadura o una aprehensión importante, decide qué se hace con las mujeres y hombres prisioneros, quiénes serán presentados al Ministerio Público y quiénes serán trasladados a alguna cárcel clandestina o al Campo Militar Número Uno." [Castellanos, Laura, op. cit., pág. 268.]

31 El "pocito" consistía en la inmersión constante y prolongada de la cabeza del torturado en agua, casi al punto de morir por asfixia. El "pollo rostizado" implicaba atar de pies y manos a un sujeto, el cual se colocaba encima de un palo con otro amarre desde los genitales. El individuo tenía que cuidar su equilibro, para no perder sus partes íntimas.

32 Citado en Ramírez, Javier. "La Brigada Blanca. Expediente completo de sus integrantes". Bajo palabra, Número 20 (200 I): pág. I I.

33 Mendoza García, Jorge, op. cit., pág. 165. 
es un indicio de los altos niveles de crueldad a los que llegó Nazar Haro en su combate encarnizado contra el "enemigo interno".

Para inicios de la década de 1980, toda la maquinaria contrainsurgente dio sus frutos. La Liga estaba prácticamente destruida como organización, si bien no fue hasta 1990 cuando desapareció formalmente. En general, todos los movimientos armados fueron reducidos al mínimo. Junto a la fuerza represiva, el gobierno dispuso medidas de consenso que debilitaron aún más a las guerrillas. Tal fue el objetivo de la Ley de Amnistía, expedida en 1978, que permitió a los guerrilleros desencantados con la lucha armada poder reintegrarse a la vida civil. El aislamiento de las guerrillas de su base social, resultado de los constantes golpes en su contra, las obligó a optar por la militarización sobre el trabajo de masas, lo que terminó por operar en su contra, ya que los sectores más radicalizados ajusticiaron a los moderados y a todo aquel que fuera considerado un traidor por buscar la amnistía. La guerra sucia triunfó y, con ello, el olvido de los crímenes políticos del pasado.

Desafortunadamente para Nazar Haro, el aniquilamiento de las guerrillas acompañó a su propia debacle. Amparados por la impunidad que les otorgó el sistema político, los cuerpos de seguridad no sólo se encargaron de combatir a la insurgencia, también se asociaron al narcotráfico y a otros negocios ilícitos con el fin de enriquecerse. El Tigre no fue la excepción, vinculándose a una banda que robaba automóviles de lujo en California para traerlos a México. La CIA intentó ocultar en la medida de lo posible la complicidad de Nazar en el asunto, ya que lo consideraba "un contacto esencial" en México debido a los intereses mutuos con Estados Unidos en materia de seguridad. ${ }^{34}$ Como el caso se ventiló públicamente, Nazar se vio obligado a renunciar de la dirección de la DFS en enero de 1982. Entonces se retiró a la vida privada, abrió una oficina particular y realizó investigaciones privadas para empresarios de diversa índole.

\section{Reflexión final}

En 200 I, bajo el gobierno de Vicente Fox, se creó la Fiscalía Especial para Movimientos Políticos y Sociales del Pasado (FEMOSPP), con el objetivo expreso de investigar los crímenes políticos cometidos durante la guerra sucia. La fiscalía realizó su primera consignación el 21 de abril de 2003 contra dos de los emblemas de la contrainsurgencia: Luis de la Barreda y Miguel Nazar Haro. Casi un año después, el 18 de febrero de 2004, parecía que finalmente el juicio de la historia alcanzaba a El Tigre. Ese día fue detenido bajo la acusación de ser responsable de la desaparición de Ignacio Salas Obregón y Jesús Piedra Ibarra. Nazar, quien tenía ochenta años, fue trasladado al penal de Topo Chico en la ciudad de Monterrey, donde se agudizaron sus problemas de salud. En noviembre de ese año le fue concedido el arraigo domiciliario debido a su edad avanzada y fue trasladado a su residencia en la capital del país.

34 Aguayo Quezada, Sergio, op. cit., pág. 236. 
Pronto se esfumó el hito esperanzador con el que la Femospp inició su tarea de lograr una justicia negada por décadas. El órgano costó un total de 300 millones de pesos y sólo se dictaron veinte órdenes de aprehensión contra diversos individuos partícipes de la guerra sucia, siendo la más destacada la realizada al ex presidente Luis Echeverría, quien, al igual que Nazar Haro, fue sometido a arraigo domiciliario por su avanzada edad. Al final, todos los acusados fueron exonerados de los crímenes que se les imputaban. En el caso de Nazar, ello ocurrió el 30 de septiembre de 2006. Después de un pésimo desempeño, donde lo único rescatable fue el Informe histórico a la sociedad mexicana (2006), en donde se condensó toda la historia de la guerra sucia, la Femospp desapareció en marzo de 2007. Su fracaso fue sinónimo del triunfo de la impunidad, que Nazar Haro gozó hasta el día de su muerte, el 26 de enero de 2012.

La muerte impune de Miguel Nazar Haro es señal de la urgencia del establecimiento de una política de la memoria que recupere los crímenes políticos del pasado, con el objetivo de que la sociedad mexicana se sienta comprometida a evitar que caigan en el olvido y, por el contrario, sean objeto de la justicia. Un primer paso en esta tarea es conocer las verdaderas dimensiones que alcanzó el terrorismo de Estado en México entre las décadas de 1960 y 1980, planteamiento que vuelve necesario el estudio y presentación ante la sociedad de toda la maquinaria de aniquilamiento que el Estado implementó contra quienes consideró sus enemigos. De ahí la necesidad vital de recuperar la trayectoria criminal de Nazar Haro y otros artífices de la guerra sucia, en el sentido de ser ellos los principales responsables de la violencia estatal que desangró al país por cerca de dos décadas. Sólo haciendo frente a ese pasado oscuro, olvidado por la memoria oficial, los mexicanos podrán darse a la difícil tarea de recomponer el tejido social roto y reparar, en la medida de lo posible, el daño ocasionado a las víctimas.

\section{Fuentes primarias}

Castillo García, Gustavo. "Comunismo, una amenaza para el país; tenía 700 jóvenes armados: Nazar Haro". La Jornada, Distrito Federal, domingo 27 de enero de 2013.

"Los guerrilleros, aventureros que querían el poder". La Jornada, Distrito Federal, miércoles 5 de febrero de 2003, 18-19 págs.

"Especial Nazar Haro, un tigre que murió en su propia jaula". El Universal, sábado 28 de enero de 20 12. Disponible en: <http://www.eluniversal.com.mx/notas/825789.html> (6 de mayo de 20 I3).

Petrich, Blanche. "Nazar enloquecía cuando torturaba, narra un ex integrante del MAR". La Jornada, Distrito Federal, domingo 9 de febrero de 2003, 10 págs.

Ramírez, Javier. "La Brigada Blanca. Expediente completo de sus integrantes". Bajo palabra, Número 20 (200 I): 4-33 págs. 


\section{Bibliografía}

Aguayo Quezada, Sergio. La charola. Una historia de los servicios de inteligencia en México. México, D.F.: Grijalbo, 2001,413 págs.

Castellanos, Laura. México armado 1943-1981. México, D.F.: Ediciones Era, 2011.

Condés Lara, Enrique. Represión y rebelión en México (1959-1985). Tomo I. México, D.F.: Miguel Ángel Porrúa, Benemérita Universidad Autónoma de Puebla, 2007.

Feierstein, Daniel. "Guerra, genocidio, violencia política y sistema concentracionario en América Latina" en Terrorismo de Estado y genocidio en América Latina. Daniel Feierstein (compilador). Buenos Aires: Prometeo Libros, Programa Naciones Unidas para el Desarrollo, 2009.

Hirales, Gustavo. Memoria de la guerra de los justos. México, D.F.: Cal y Arena, 1996.

Mendoza García, Jorge. "La tortura en el marco de la guerra sucia en México". Polis, Volumen 7, Número 2 (20I I): págs. I39-179.

Pineda Ochoa, Fernando. En las profundidades del mar (El oro no llegó de Moscú). México, D.F.: Plaza y Valdés, 2003, 288 págs.

Scherer García, Julio. "Los patriotas. De Tlatelolco a la guerra sucia” en Los patriotas. De Tlatelolco a la guerra sucia. México, D.F.: Aguilar, 2004, págs. 5- 139.

Sierra, Jorge Luis. "Fuerzas armadas y contrainsurgencia (1965-1982)" en Movimientos armados en México, siglo XX. Verónica Oikión Solano y Marta Eugenia García Ugarte (editoras). Zamora, Michoacán: El Colegio de Michoacán, Centro de Investigaciones y Estudios Superiores en Antropología Social, 2008, págs. 36 I-404.

Torres, Jorge. Nazar, la historia secreta. El hombre detrás de la guerra sucia. México, D.F.: Debate, 2008. 